Ethiopian Journal of Environmental Studies \& Management 9(Suppl. 1): 928 - 937, 2016.

ISSN:1998-0507

doi: http://dx.doi.org/10.4314/ejesm.v9i1.11S

Submitted: September 07, 2016

Accepted: December 02, 2016

\title{
ECOSYSTEM FUNCTIONS AND SERVICES OF CLOUD AFROMONTANE FORESTS IN ETHIOPIA
}

\author{
ANTENEH SHIMELIS \\ Department of Zoological Sciences, Addis Ababa University, Ethiopia \\ Email: anteraptor@yahoo.co.uk
}

\begin{abstract}
Using meta data on crop output, crop output together with productivity of animal husbandry, surface water volume, ground water volume and cover of cloud wet afromontane forests in selected four regions which are major food producers in Ethiopia the functions and the services of the forests were modelled. Forest cover significantly and positively explained agricultural productivity, surface and ground water volume in Ethiopia. In similar regression modeling it was determined that food productivity across regions was result of the volume of surface water and ground water. This clearly indicates unwarranted destructive alteration of the forest cover in the country would have unprecedented negative effects thereby exasperating natural disasters which ultimately will cause a negative shock to the overall economy. Furthermore increasing forest cover through the planting of trees and others would have significant positive effect on the economy which enhances the wellbeing of a significant portion of the population in the country.
\end{abstract}

Key Words: Ecosystem Functions, Ecosystem Services, Ethiopia

\section{Introduction}

Natural ecosytems provide essential ecological, socio-cultural and economic values to humans (Constanza et al., 1997; de Groot et al., 2002). These benefits consist of a mix of goods and services provided by mutlifunctional landscapes which therfore are called "natural capitals of humans" (de Groot et al. 2010). As often is the case, all these benefits are not fully taken in to account in environmental planning and decison making resulting in the conversion of productive multifunctional landscapes in to single function land use types. Yet increasingly, studies have shown that the total value of multi-functional use of natural and seminatural landscapes is often economically more beneficial than the converted systems. But humans around the world continue to destroy their "natural capital" at the peril of even their own walfare. One main reason behind this destructive behaviour is the under-valuation of benefits of natural and semi-natural landscapes which emanates from the deficiency of the market based economic analysis in expressing the importance of these landscapes in monetary terms (de Groot et al., 2010). There is still a 
considerable lack of data on the many functions and values of natural and seminatural ecosytems, thus decisons are continued to be made on the basis of incomplete information. Market failures play major role in driving loss of ecosystems and landscapes because most of the benefit of natural and semi-natural landscapes are seen as non-marketed externalities, which accure to local socities at "at large" and at global scales. Conversion of these landscapes usually only makes narrow economic sense because the benefits from the land use change usually go to private or corporate interest groups while the costs (nonmarketed externalities) are burdened up on a diffused group of multi-stakeholders and future generations (de Groot et al., 2010). While conversions of natural landscapes to single function sytems may be rational over the short term with respect to public or private policy objectives, over the long term many result in both economic inefficiency and erosion of natural services (Turner and Jones, 1991 as cited in de Groot 2005). An effective and sustainable utilization of a given landscape is dependent up on a well informed planning and decison making process that give due empahsis to the regulation functions that provide the necessary preconditions for all other ecosystem functions (de Groot et al., 2010). In theory the number of regulation functions would be almsot be unlimited but for landscape planning only those regulation functions that provide services which have direct and indirect benefits to humans are considered (such as maintainace of clean air, water and soil, prevention of soil erosion, biological control services). Another set of important functions relate to production of living biomass that humans exploit. The goods and services rendered to humans through these functions are valued in ecological and economic terms (de Groot et al., 2010). Such valuation estblaishes human utilization of a landscape in a firm footing.

Ethiopia is one of the key country's where a rich assemblage of biophysical resources with very high international and national importance are found. Currently the country is facing recurrent ecological disaster characterised by loss of human livelihood. This paper asserts that the direct cause of natural resource mismanagement is the lack of detailed ecological knowledge in the country at large. To make conservation efforts in the country economically sensible it is important to quantify the functions and services of ecosystems and to clearly express scientifically the benefits accrued by humans through the preservation and operational functioning of natiural systems through man made investments. This principally is the driving hypothesis of the paper that the backbones of the economy of the country are outcomes of the natural systems which until now are preserved by humans. Towards this end the positive explanatory value of cloud wet afromontane forests to patterns of output in agriculture, animal husbandry and water provisions were explored and modelled in this paper.

\section{Study Area}

The paper is based on meta data published for food producing regions namely Amhara, Oromiya, Southern Nations and Peoples and Tigray regions in Ethiopia (Figure 1). As depicted in figure 1, most of the highlands in Ethiopia are forested. 
The Amhara administartive region is is located in the northwest, centre and northeast Ethiopia sharing borders with Tigray on the north, Afar in the east, Oromiya on the south, and Benshangul Gumuz on the west (Shimelis et al., 1996). Annual rainfall ranges from less than $500 \mathrm{~mm}$ to over $1,600 \mathrm{~mm}$ a year with bimodal pattern to the east of the Nile River valley in Shewa and Wello, and a monomodal pattern to the northwest of the Nile river in Gojam and Gondar. The topography of the region is very variable ranging from lowland around $1,000 \mathrm{~m}$ asl at the bottom of the eastern escarpement and in the river valleys rising up to the top of Ras Dejen at $4,620 \mathrm{~m}$ asl. Most of the residents of the Amhara region lead sedentary lives subsiting on agrarian mode of life. In such farms there is substantial activity in animal husbandry. There is a substantail amount of land covered with various vegetation types that qualifies as high importance for conservation. The forests which are the focuses of this study in the region constitute highland afromontane species such as Hagenia abyssinica, Olea europea subsp. cuspidata and Juniperus procera at higehr altitudes with Podocarpus falactus, Allophylus abyssinicus coming in lower down. Around $3,000 \mathrm{~m}$, the large trees are replaced by Erica arborea, Hypericum revoltum and Giant lobelia spp. There are also extensive patches of the endemic Kniphophia foliosa and Festuca grass. The herb layer within the forests is also considered rich in species. Mostly the cliffs above these highland forests have small shruby plants and grass tussocks clinging to them.

Oromiya region is located $03^{\circ} 20^{\prime}$ $10^{\circ} 35^{\prime} \mathrm{N}$ and $34^{\circ} 05^{\prime}-43^{\circ} 11^{\prime}$ with its southern part very near the equator (Shimelis et al., 1996). The southern parts of the region, particulalrly Borena, have a bimodal rainfall with the heaviest and most reliable rains in April and May and a less reliable amount in October. The central and eastern areas are also bimodal but the main rain is from June/July to September and the small rain is from March to April. In the southwest and west, there is only one long rainy season from around April/May to October. The region is characterized by immense geographical diversity consisting of high and rugged contoured mountains disected by the great East African Valley. The high mountains include Tullu Deemtu in Bale $(4,307 \mathrm{~m}$ asl), Kecha (4,245 m asl), Ankole (4,300 $\mathrm{m}$ asl) in Arsi, Gra Muleta in Harrarge (3, $492 \mathrm{~m}$ asl) and Badda Roge in Shewa $(3,350 \mathrm{~m}$ asl $)$. The wet afromontane forests which are the focuses of the study in this paper are charcterized by species such as Podocarpus falactus, Crorton macrostachyus, Hagenia abyssinica, Ilex mitis, Olea capensis, Schfflera abyssinica, and Syzigium guineese subsp. afromontanum. Once nomadic people of pastoralists, the majority of the Oromo are sedentary subsitence farmers. Though the inhabitatnts of the more arid areas are cattle breeders.

To the north and east of the Southern Nations and Peoples region is found Oromiya, Kenya to the south, and the Sudan and Gambella region to the southwest and west (Shimelis et al., 1996). The western parts have one rainy season from May/June to September/October bring an annual rainfall of $1,000 \mathrm{~mm}$. The border regions along the south with Kenya have around $500 \mathrm{~mm}$ of rain a year, with most rain 
falling between March and May, and smaller, less reliable amount around October. The northern parts of the region have two good rainy seasons bringing an annual average of over $1000 \mathrm{~mm}$. The region has areas that are highly variable in topography ranging from $350 \mathrm{~m}$ asl at Lake Turkana to over $4,000 \mathrm{~m}$ asl on the Guge mountains. The region is disected by both the Rift Valley and Omo River Valley System. The forests of the region are charachterized by species such as Erica arborea, Rosa abyssinica, Juniperus procera, Shifflera abyssinica, Croton macrostachyus and and Ekebergia capensis. The people of the region in the highlands subsist on agriculture while those in the dirier parts of the region are livestock breeders.

Tigray region is lying between latitudes $12^{\circ} 17^{\prime} \mathrm{N}$ and $14^{\circ} 52^{\prime} \mathrm{N}$ and longitudes $36^{\circ} 25^{\prime} \mathrm{E}$ and $41^{\circ} 49^{\prime} \mathrm{E}$ (Shimelis et al., 1996). The main rainy season in the region is in summer. But the eastern parts have more pronounced period of rains in Spring. In the southeastern plains of Almata, the Spring rains from a second growing season are suffcient to cultivate some highland crops. In the rest of the region there are sufficient Spring rains. The topography of Tigray is determined by the state of erosion of the overlaying volcanic rocks, by the northwestern slant of the Northern Ethiopian massif, and by the orgraphic features associated with the formation of the Great Rift Valley. The forest areas of the region are charachterized species such as Podocarpus falactatus, Millettia ferruginia, Celtis africana, Ekebergia capensis, Prunus africana, Cordia africana, and Ficus spp. Rainfed agriculture and animal husbandery at sendatery farms predominates the mode of life of the people of the region.

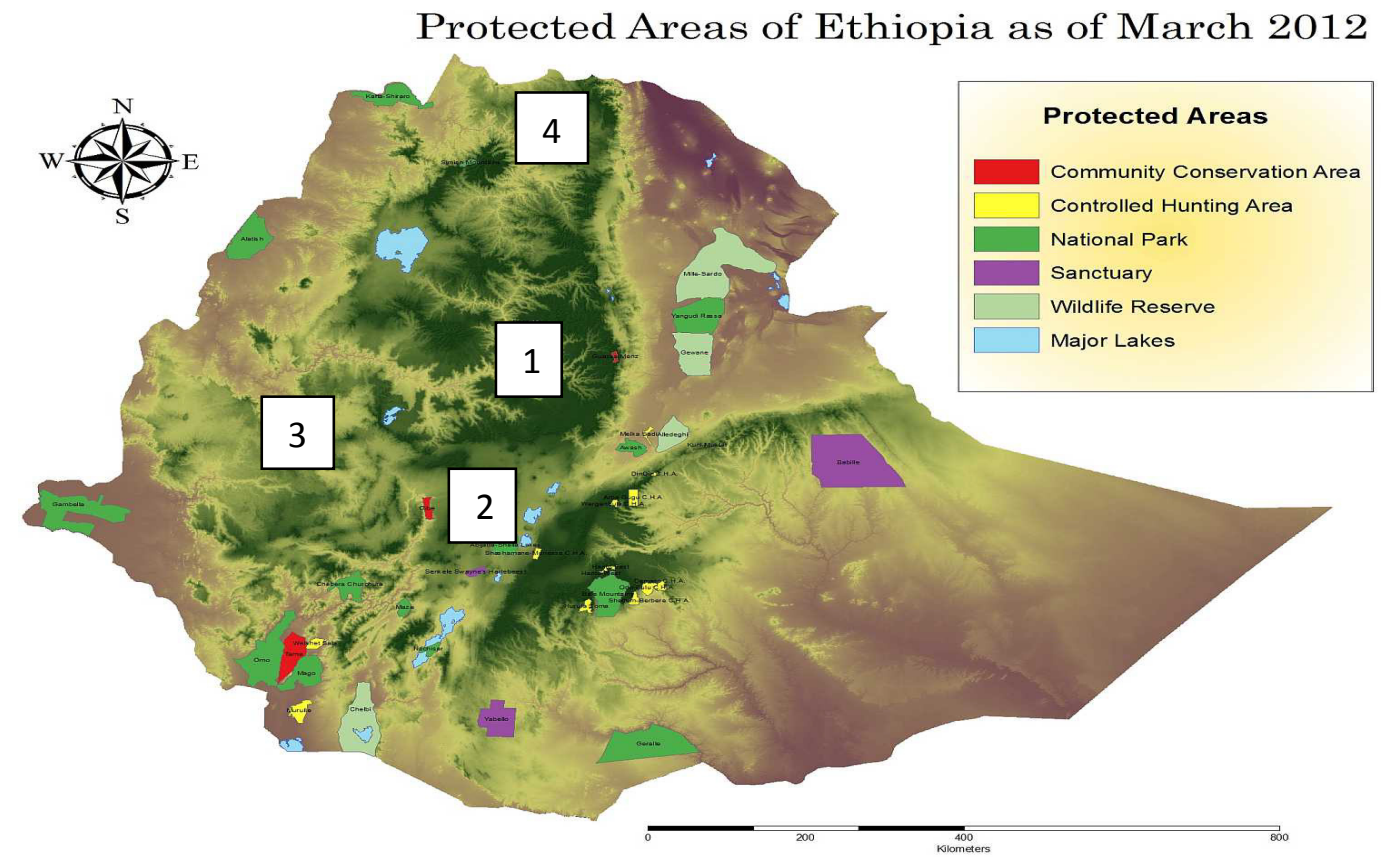

Figure 1: The study area including the regions studied coded numerically (1=Amhara, $2=$ Oromiya, $3=$ Southern Nations and People and $4=$ Tigray) and protected areas overlayed on the satelite image of the vegetation zones particularly. 


\section{Methods}

Published materials (Shimelis et al., 1996; EWNHS 2001; Aulachew et al., 2007) were gleaned through for meta data on crop output, crop output together with productivity and animal husbandry, surface water volume, ground water volume and cover of wet afromontane cloud forests in Ethiopia. The later was used to explain patterns in the former five in a multiple of univariate regression modeling.

As a predictor variable the average area extent of forest patches that delimited areas of IBAs in Ethiopia was used as samples from which an index of forest cover was calculated for each of forested regions. This was used as an explanatory variable in regression of percent crop output for each of the four regions which was calculated from what was published in the literature as the percent difference in productivity of regions relative to the Amhara region. The same was true for the percent index that combined outputs from crop production and animal husbandry. Total volumes of surface water as found in rivers was calculated for the regions and also the same was done for ground water when used in the linear regression modelling.

\section{Results \\ Contribution of Forest Cover to Regional Crop Output}

Patterns in crop output were modeled against cover of wet afromontane cloud forests in Ethiopia (Figure 1). The best fit of the model explained significantly $(\mathrm{P}<$ 0.01 ) more than $72 \%$ of the variation in crop output across regions which are known to have some level of the type of tropical wet forest. The positive effect of the explanatory forest variable indicated agriculture in the country benefitted hugely from forests and the level of observed effect on crop output can be considered as one of the goods and services provided to humans by forest ecosystems in the country.

Contribution of forest cover regional crop and livestock productivity

The merging of animal husbandry with crop cultivation in the percent index had little reduced effect on the regression model that used forest variable to explain the observed pattern (Figure 1). This particular model explained positively with statistical significance $(\mathrm{P}<0.01)$ about $63 \%$ of the variation in the data set of the outcome variable. Despite the slight difference between the two models the result showed animal husbandry is also an outcome of forest functions as one of the services rendered to humans. 
Ecosystem Functions and Services of Cloud Afromontane Forests.................ANTENEH

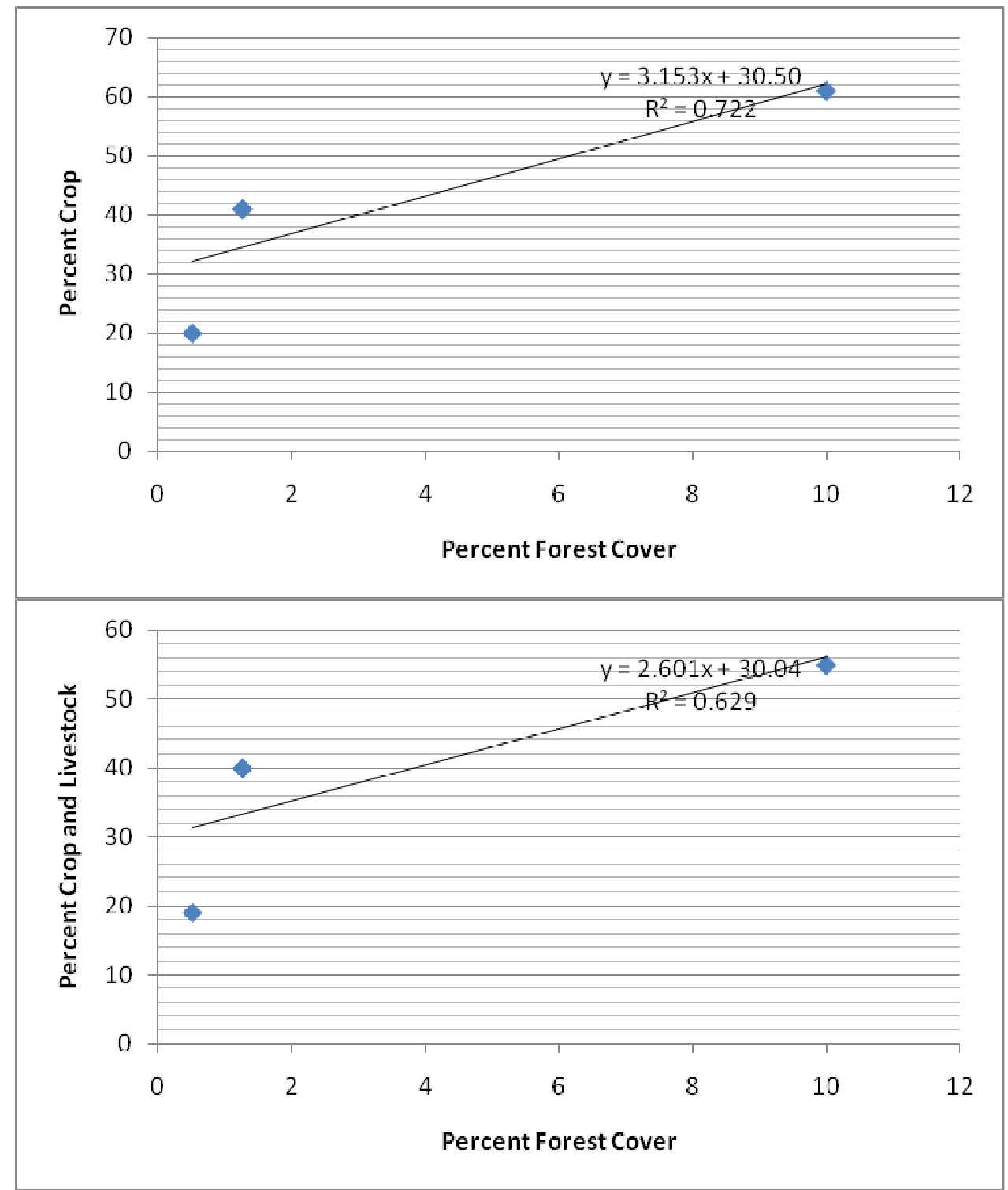

Figure 1: The resulting effect of having forest cover on crop output and livestock productivity

Contribution forest cover to surface water volume

Surface water volume, particularly that in rivers, was modeled as an outcome of forest cover (Figure 2). The explanatory variable predicted significantly $(\mathrm{P}<0.01)$ the volume of surface water by explaining more than 94 $\%$ of the observed variation across forested regions of Ethiopia. The positively significant model indicated the amount surface water volume is dependent upon how well regions are covered with 


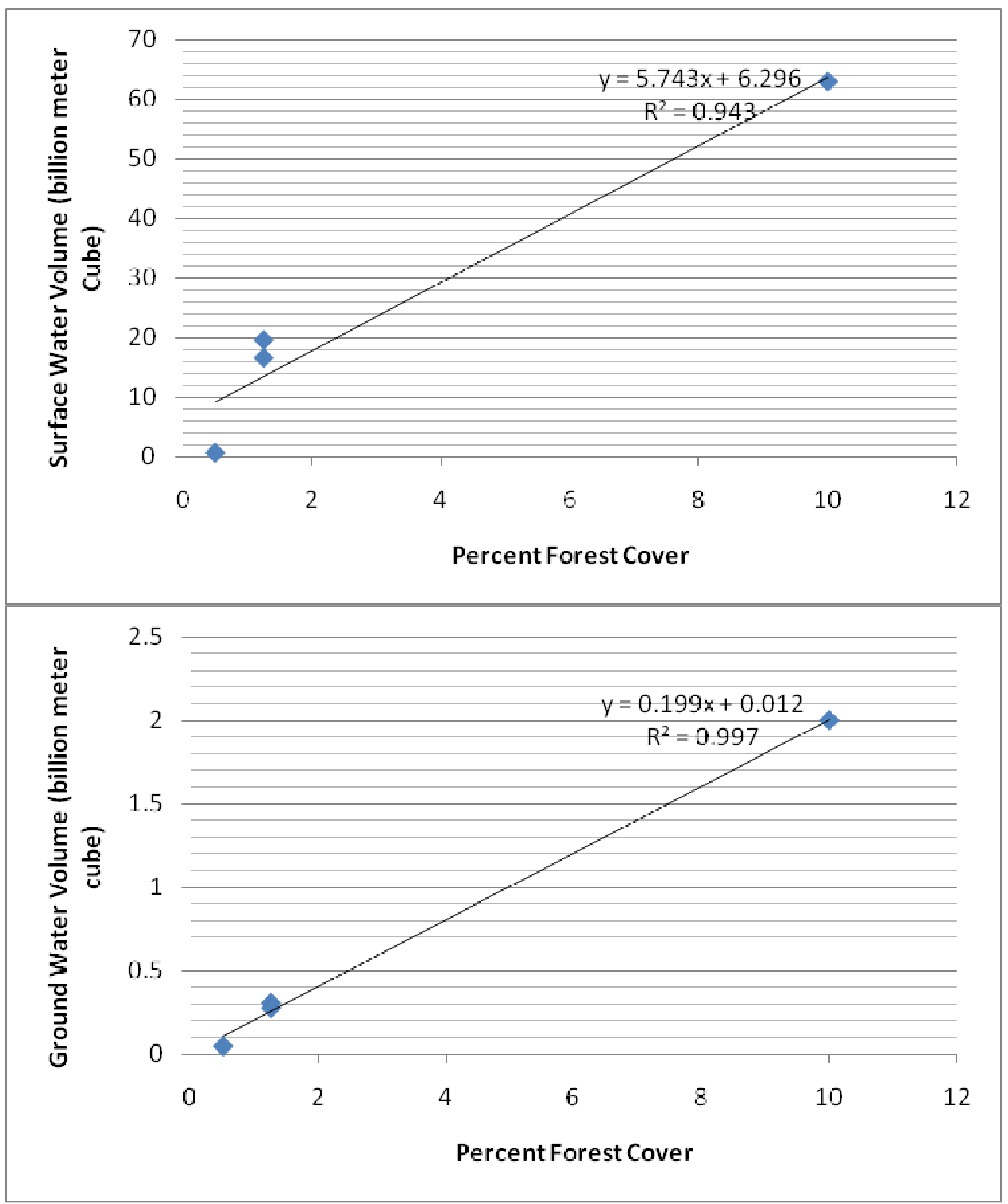

Figure 2: Accumulation of surface and ground water as result of forest cover

\section{Contribution of forest cover to ground water volume}

The volume of ground water had a pattern of an ascending order as result of increase in forest cover (Figure 2). In the model more than $99 \%$ of the variation observed in ground water volume data set was explained significantly at $\mathrm{P}<0.01$. The result indicated ground water accumulation and the causative recharge are highly dependent on the availability of forest and the magnitude of its cover at a given region.

Contribution of surface water volume to crop output

Modeling percent productivity of crops against surface water volume indicated the latter had significant $(\mathrm{P}<$ 0.01 ) explanatory value (Figure 3 ). In this model crop productivity increased 
significantly with increases in surface water volume. The best fit of the model accurately predicted $89.9 \%$ of the observed data set.

Contribution of Ground Water Volume to Crop Output
The volume of water in the ground did also have significant $(\mathrm{P}<0.01)$ positive effect on crop output (Figure 3). The model's best fit represented 76.6 of the observed data set.

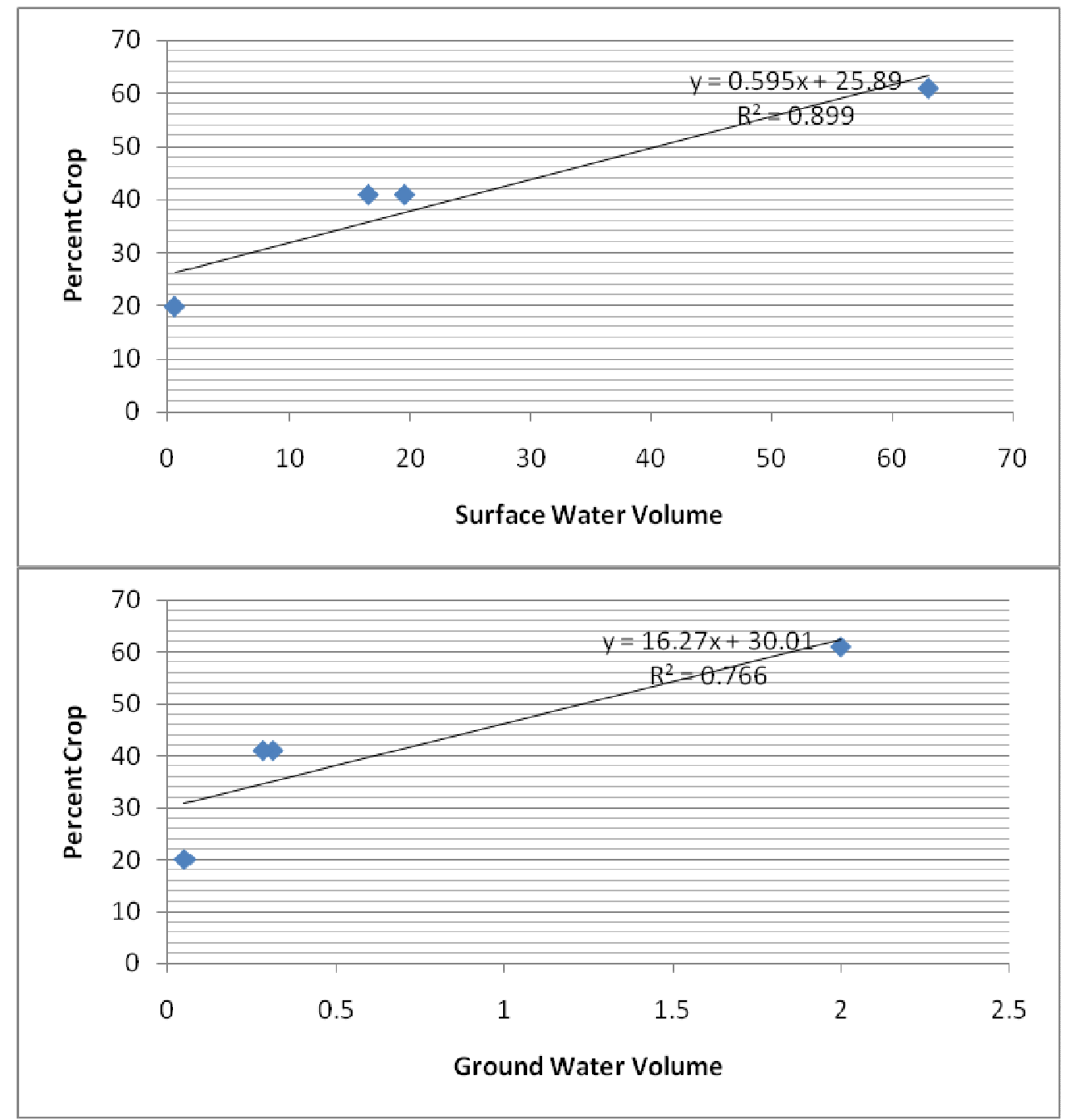

Figure 3: Contribution of surface and ground water volume in explaining observed patterns in crop productivity across regions considered.

Contribution Surface Water to crop and livestock productivity

$83.2 \%$ of combined crop and livestock productivity was explained positively by volume of surface water in the regions with forest cover (Figure 4). In this model the two modes of food production had significant increasing pattern in output along a dimension of increase in surface water volume. 


\section{Contribution of Ground Water to Crop and Livestock Productivity}

When modeled against ground water volume the output in crop and livestock increased significantly $(\mathrm{P}<0.01)$ with increases in the magnitude of the predictor (Figure 4). About $68 \%$ of the data variation was explained by the model's best fit.

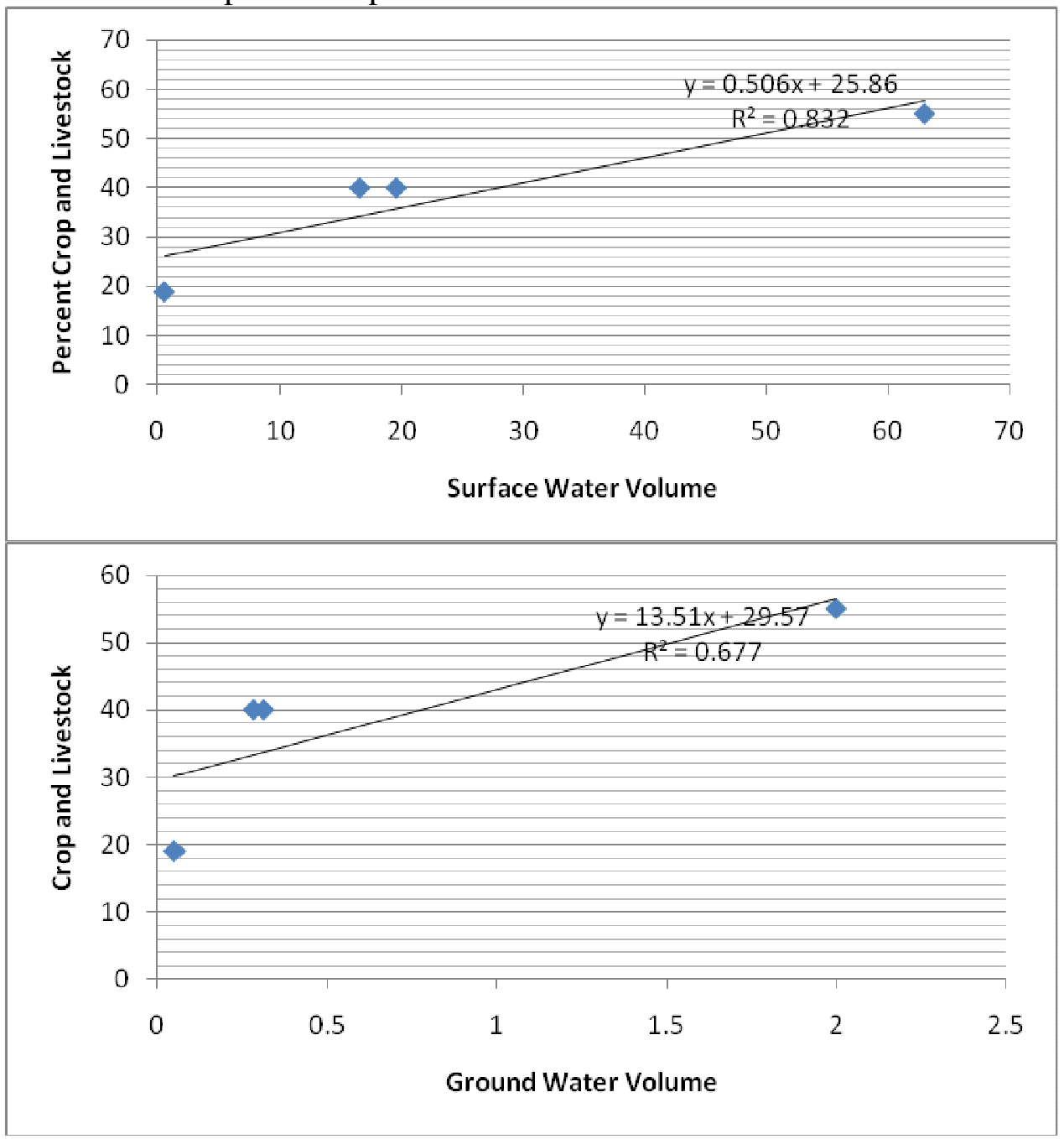

Figure 4: Patterns in crop and livestock productivity explained by surface and ground water volumes across regions of Ethiopia.

\section{Discussion}

Ecosystem functions are regulatory processes that sustain the whole natural system itself including species and communities and result in services that enrich human life (de Groot et al., 2002; Badola and Hussien 2005; Sodhi and Ehrlich 2010). Ecosystem functions that result in to goods and services to humans include those that are regulatory in nature such as a predator's optimal suppression of prey populations which leads to stability in the latter, habitat provision and actually producing the goods and services as extended from de Groot et al. (2002). The resulting goods and services in simple terms are food, water, and shelter to humans. The stress or 
disruption on the functions would substantially reduce the ecosystem goods and services which causes deterioration of the health of human well being (Corvalan et al., 2005).

Despite the fact that detailed small scale data is needed to determine exactly the operational functions of the forests considered in this paper results of the analysis indicated productivity in all dimensions of agriculture are results of the presence and extent of the forests in the four regions. Small scale, but similar findings in forest services by way Mangroves in India were demonstrated as the consequent results of the primary predictor that significant increase in food production was observed when adjacent villages were considered (Badola and Hussien 2005). The evident match between forest cover in Ethiopia (Vreugdenhil et al., 2012) and levels of precipitation (Aulachew et al., 2007) across the different parts of the country indicate that the forests play significant role in the maintenance of a healthy climate and the resultant surface and ground water volumes are actually highly interrelated with it.

\section{References}

Awulachew, S.B., Yilma, A.D., Loulseged, M., Loiskandl, W., Ayana, M. and Alamirew, T. (2007). Water Resources and Irrigation Development in Ethiopia. Colombo, Sri Lanka: International Water Management Institute. 78p. (Working Paper 123)

Badola, R. and Hussien S.A. (2005). Valuing ecosystem functions: an empirical study on the storm protection function of Bhitarkanika mangrove ecosystem, India.
Environmental Conservation, 32(1): 85-92.

Constanza R., Wilson, M.A., Troy, A., Voinov, A. and Liu, S. (2006). The Value of New Jersey's Ecosystem Services and Natural Capital. New Jersey Department of Environmental Protection

Corvalan C., Hales, S. and McMichael, A. (2005). Ecosystems and Human Well being. A Health Synthesis. World Health Organization.

de Groot, S.R., Willson, A.M. and Bouman, J.M.R. (2002). A typology for the classification, description and valuation of ecosystem functions, goods and services. Ecological Economics, 41:393-408.

de Groot, S.R., Alkemade, R., Braat, L., Hein, L. and Willemen, L. (2010). Challenges in integrating the concept of ecosystem services and values in landscape planning, management and decision making. Ecological Complexity.

Ethiopian Wildlife and Natural History Society. (2001). Ethiopia in Important Bird Areas of Arica and Related Islands. BirdLife International.

Shimelis, A., Allport, G., Atkins, J., Fishpool, L., Wondafrash, M., Robertson, P., Demissew, S., Dejene, S., Edwards, S., Wolde Mariam, T., Nigussie, T. and Dellelegn, Y. (1996). Important Bird Areas of Ethiopia: A first inventory. Ethiopian Wildlife and Natural History Scoiety.

Sodhi, N. and Ehrlich, R.P. 2010. Conservation Biology for All. Oxford University Press.

Vreugdenhil, D., Vreugdenhil, M.A., Tilahun, T., Shimelis, A., Tefera, Z. (2012). Gap Analysis of The Protected Areas System of Ethiopia. Ethiopian Wildlife Conservation Authority. 